\title{
Hybrid Electric Vehicle with Matrix Converter and Direct Torque Control in Powertrains Asynchronous Motor Drives
}

\author{
Sorin Ioan Deaconu ${ }^{1, *}$, Marcel Topor ${ }^{1}$, Gabriel Nicolae Popa ${ }^{1}$ and Feifei $\mathrm{Bu}^{2}$ \\ ${ }^{1}$ Electrical Engineering and Industrial Informatics Department, Politehnica University, Timisoara, \\ Romania \\ ${ }^{2}$ University of Aeronautics and Astronautics, Nanjing, China
}

\begin{abstract}
Electric transportation has made rapid developments and significant steps toward the full electrical powertrain systems. With the increased use of electric vehicles energy conversion systems several technologies have been developed and reached a high degree of performance. Since electric vehicles and hybrid are the more cost competitive technology available today, the evolution toward a more reliable powertrain combining different electric powertrain systems is needed. Induction machine and permanent magnet generators/motors integrated powertrains have some significant advantages over other types of systems such as no need of excitation, low volume and weight, high precision, and no use of a complex gearbox for torque/speed conversion. A electric vehicle powertrain for EV propulsion with a induction motor and a matrix converter is proposed in this paper. The induction motor is controlled using the direct torque flux algorithm. The traditional power conversion stages consist of a rectifier followed by an inverter and bulky DC link capacitor. It involves 2 stages of power conversion and, subsequently, the efficiency of the overall EV is reduced because of power quality issues mainly based on total harmonic distortion. The proposed solution incorporates a matrix converter is mainly utilized to control the induction electric motor for propulsion. The matrix converter is a simple and compact direct AC-AC converter. The proposed EV with matrix converter is modeled using PSIM.
\end{abstract}

\section{Introduction}

Transportation is a key sector in every country economy. Electric vehicles are several times more efficient in converting energy into vehicle movement than conventional gasoline and diesel vehicles (Benachour, 2016; Venugopal, 2010; Mardani, 2015; Fazli, 2017; Sebtahmadi, 2015; Faraji, 2011). They are much more compatible with renewable energy sources and in combination with this represent a very serious pollution reduction technology. They can produce no emissions at the vehicle tailpipe and much lower life-cycle ("well to wheel") emissions. For this reason there is very large pressure from businesses, governments, and nongovernmental organizations in order to make the orientations toward the electric vehicles in order to dramatically lower oil use, to reduce carbon emission pollution, eliminate city air pollution, and force a sustainable economic development. If the world is to avoid worst-case global climate-change effects the longterm planning scenarios indicate that the global vehicle fleet will have to be almost entirely made up of electric vehicles, powered mostly by renewable sources, and this at very quick pace, by 2050 .

Various technologies have been developed in automotive industry as the result of the effort to further improve electric powertrains for $\mathrm{EV}$ based on the permanent magnet synchronous machines (PMSM) and induction machines (IM). When compared to conventional machines, the Induction machines have the advantages of being robust in construction, not requiring an additional power supply for magnetic field excitation, and requiring less maintenance. A variable-speed HEV including a IM offers advantages over the constant-speed approach, such as maximum power-point tracking capability and reduced acoustic noise at lower speeds (Davari, 2009; Peng, 2015).

Fig. 1 shows the block diagram of the proposed electric powertrain, constant speed permanent magnet synchronous generator connecting a three phase power bus and a matrix converter with a three phase induction machine traction motor. When compared with conventional AC-DC-AC converters, the proposed HEV with the matrix converter has the following advantages:

- The matrix converter provides almost sinusoidal waveforms in the input and output sides.

- The absence of a DC link capacitor means that the matrix converter has a compact design and less weight (Faraji, 2011; Xiao, 2009).

- At low switching frequencies, the efficiency of matrix converter-based $\mathrm{HEV}$ is higher than that of conventional powertrain drives, and the matrix converter has faster dynamic response (Li, 2009). 
The matrix converter is a highly controllable power converter and allows for instant independent control of the output voltage magnitude and frequency and the input power factor (Li, 2009; Faraji, 2011). The intermediate DC link creates an electrical decoupling between the PMG and the grid. Hence, it requires a separate controller for compensation of stored kinetic energy in the generator (Zhang, 2017).The matrix converter does not require a DC link.

This paper focuses on the modeling of an electric powertrain with induction machine driven by a with a matrix converter, developed in PSIM. The simulation is analyzed based on traction motor speed, generator output voltage, and frequency for different values of input reference velocities. Dynamic analysis is also conducted for sudden variations of wind speed. The performance of the matrix converter is controlled using a special optimum commutation table.

\section{Components of Proposed Powertrain}

The powertrain is based on the use of an indirect matrix converter. The overall block diagram of developed indirect matrix converter (MC) and IM based HEV energy conversion system is shown in Fig. 1. It consists in matrix converter based electric drive; a PMSM permanent magnet generator operated a fixed speed a three phase inverter/ battery charger. We will focus here only on the control of the matrix converter and the combination between the direct torque control and the matrix converter control for the induction machine.

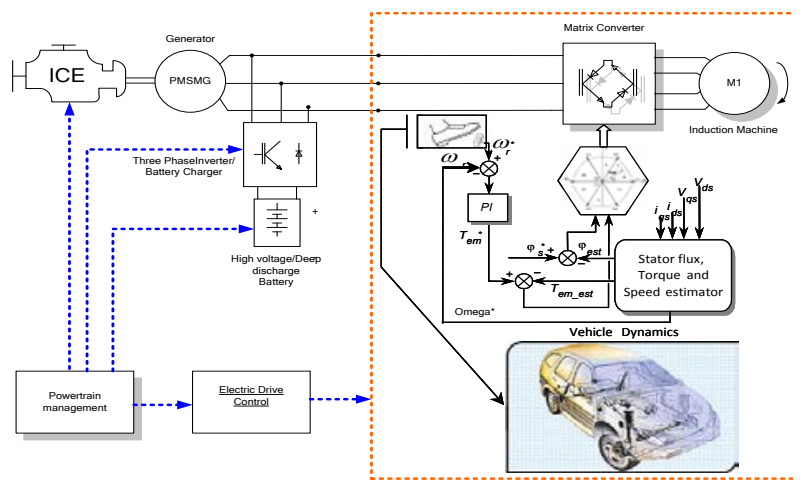

Fig. 1. HEV integrating matrix converter and direct torque control IM electric drive.

\section{Indirect Matrix Converter Model}

In this paper we have used the PSIM software to analyze the performance of the matrix converter coupled with an induction motor for electric propulsion. The schematic of the proposed indirect matrix converter is presented in Fig. 2.

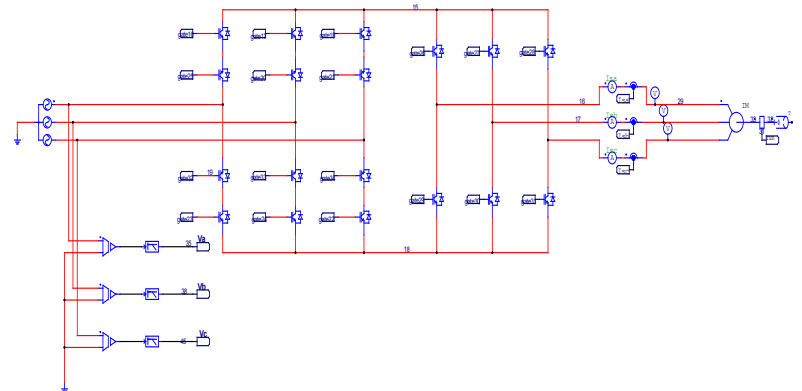

Fig. 2. Indirect Matrix Converter.

\section{Mathematical Modeling of the Matrix Converter}

The mathematic model build in PSIM of two-stage matrix converter shown in Fig. 2 is given by the matrix expression (1), resulting from the product of the instantaneous states of the rectifier stage and the inverter stage.

$$
\begin{array}{r}
{\left[V_{0}\right]_{A B C}=[S] \cdot\left[V_{m}\right]_{a b c}} \\
{\left[i_{m}\right]_{a b c}=[S]^{T} \cdot\left[i_{0}\right]_{A B C}} \\
{[S]=\left[S_{\text {inv }}\right] \cdot\left[S_{r e c .}\right]\left[\begin{array}{cc}
S_{a} & S_{a}^{\prime} \\
S_{b} & S_{b}^{\prime} \\
S_{c} & S_{c}
\end{array}\right] \cdot\left[\begin{array}{lll}
S_{A} & S_{B} & S_{C} \\
S_{A} & S_{B}^{\prime} & S_{C}^{\prime}
\end{array}\right],} \\
{\left[S_{\text {rec. }}\right]=\left[\begin{array}{ccc}
S_{A} & S_{B} & S_{C} \\
S^{\prime}{ }_{A} & S^{\prime}{ }_{B} & S_{C}^{\prime}
\end{array}\right]\left[S_{i n v .}\right]=\left[\begin{array}{ll}
S_{a} & S_{a}^{\prime} \\
S_{b} & S^{\prime}{ }_{b} \\
S_{c} & S^{\prime}{ }_{c}
\end{array}\right]}
\end{array}
$$

where $[\mathrm{S}]$ is the connection matrix of the indirect matrix converter, $\left[\mathrm{S}_{\mathrm{rec}}\right]$ is the connection matrix of the rectifier stage. $\left[\mathrm{S}_{\mathrm{inv}}\right]$ is the connection matrix of the inverter stage. If $t_{i}$ represent the conduction time of the corresponding switch $S_{i}$ during the switching period $T$, then the modulation coefficients relative to the conduction time is expressed by equation (6) where $i=$ $(\mathrm{A}, \mathrm{B}, \mathrm{C})$ for the rectifier, $(\mathrm{a}, \mathrm{b}, \mathrm{c})$ for the inverter.

$$
m_{i}=\frac{t_{i}}{T}
$$

The equations described above in "connection function" are transformed in "modulation function" and the expression of output voltage and input current are obtained in equations (1) and (2).

$$
\begin{gathered}
{\left[V_{0}\right]_{A B C}=[M] \cdot\left[V_{m}\right]_{a b c}} \\
{\left[i_{m}\right]_{a b c}=[M]^{T} \cdot\left[i_{0}\right]_{A B C}} \\
{[M]=\left[M_{i n v}\right] \cdot\left[M_{r e c .}\right]\left[\begin{array}{cc}
m_{a} & m_{a}^{\prime} \\
m_{b} & m_{b}^{\prime} \\
m_{c} & m_{c}^{\prime}
\end{array}\right] \cdot\left[\begin{array}{lll}
m_{A} & m_{B} & m_{C} \\
m_{A}^{\prime} & m_{B}^{\prime} & m_{C}^{\prime}
\end{array}\right]}
\end{gathered}
$$




$$
\left[M_{\text {rec. }}\right]=\left[\begin{array}{ccc}
m_{A} & m_{B} & m_{C} \\
m_{A}^{\prime} & m_{B}^{\prime} & m_{C}^{\prime}
\end{array}\right]\left[M_{i n v .}\right]=\left[\begin{array}{cc}
m_{a} & m_{a}^{\prime} \\
m_{b} & m_{b}^{\prime} \\
m_{c} & m_{c}^{\prime}
\end{array}\right] \text { (9) }
$$

where: $[\mathrm{M}]$ is the conversion matrix of the IMC. $\left[\mathrm{M}_{\mathrm{rec}}\right]$ is the conversion matrix of the rectifier stage. $\left[M_{i n v}\right]$ is the conversion matrix of the inverter stage.

\section{DTC Induction machine control}

In the DTC control scheme the reference voltage for space vector modulator is calculated by two hysteresis regulators. For high speed region, where stator flux magnitude has to be decreased, in parallel with the DTC structure a field weakening algorithm can be applied easily. The control of the output voltage is based on the classical DTC scheme. At each cycle period the optimum vector, eight voltage vectors will be generated by the DTC controller, according to a optimum switching Table I depending to the position of the stator flux vector and the output signals of the stator flux and torque hysteresis comparators. Once the classical DTC control scheme has selected the optimum voltage vector to be applied to the machine, it is a matter of determining the correspondent matrix converter switching configuration. The matrix converter has a special feature since it has always available two switching configurations for each VSI output vector corresponding to the classical DTC scheme. In this paper we have considered an additional constraint for the converter to comply with unity input power factor regulation. Fulfilling this objective can be achieved forcing the value of $\sin (\psi)$ to zero. The variable $\sin (\psi)$ is directly controlled by one additional hysteresis comparator shown.

In DTC torque and flux are controlled directly. In traction torque control loop is used for speed regulation. The field weakening algorithms are necessary for induction motor based traction drives in order to cover the whole speed range. Therefore, the presented algorithm is suitable for EV applications.

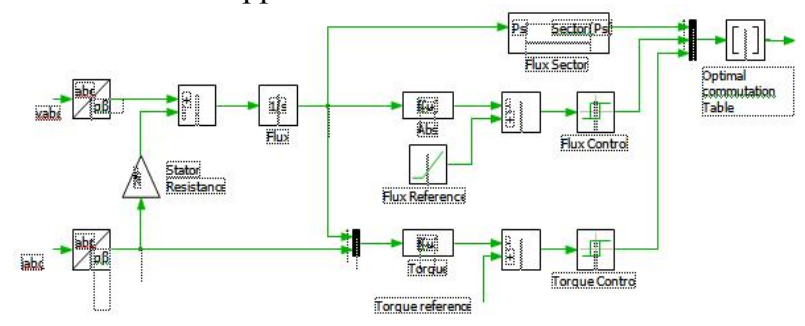

Fig. 3. Structure of the DTC control.

The basic model of DTC for induction machine motor scheme is shown in Fig. 3. At each sample time, the two stator currents $i_{s \alpha}, \quad i_{s \beta}$ and the AC bus voltage $V_{a b c}$ are sampled. Using the inverter voltage vector, the $\alpha-\beta$ components of the stator voltage space vector in the stationary reference frame are calculated as follows.

$$
\left\{\begin{array}{l}
V_{s \alpha}=V_{a} \\
V_{s \beta}=\frac{1}{\sqrt{3}}\left(V_{b}-V_{c}\right)
\end{array}\right.
$$

The $\alpha-\beta$ components of the stator current space vector are calculated using

$$
\left\{\begin{array}{l}
i_{s \alpha}=i_{s a} \\
i_{s \beta}=\frac{i_{s a}+2 i_{s c}}{\sqrt{3}}
\end{array}\right.
$$

The stator flux is a function of the rotor flux which is provides from the flux observer.

$$
\left\{\begin{array}{l}
\varphi_{s \alpha}=\sigma L_{S} i_{s \alpha}+\frac{M}{L_{r}} \varphi_{r \alpha} \\
\varphi_{s \beta}=\sigma L_{S} i_{s \beta}+\frac{M}{L_{r}} \varphi_{r \beta}
\end{array}\right.
$$

Then the magnitude of the stator flux and electromagnetic torque are calculated by

$$
\left\{\begin{array}{l}
\left|\varphi_{s}\right|=\sqrt{\varphi_{s \alpha}^{2}+\varphi_{s \beta}^{2}} \\
T_{e}=\frac{3}{2} p\left(\varphi_{s \alpha} i_{s \beta}-\varphi_{s \beta} i_{s \alpha}\right)
\end{array}\right.
$$

where $p$ is the number of pole pairs.

As shown in Fig. 2, a switching table is used for the inverter control such that the torque and flux errors are kept within the specified bands. The torque and flux errors are defined as

$$
\left\{\begin{array}{l}
\Delta T_{e}=T_{e}-\hat{T}_{e} \\
\Delta \varphi_{S}=\varphi_{S}-\hat{\varphi}_{S}
\end{array}\right.
$$

The inverter switching states are determined by the torque and flux errors according to the sector determined. The DTC modulation scheme for matrix converter is able to synthesize a higher number of voltage vectors than those used in conventional DTC with standard VSI. The corresponding switching states of the matrix converter are given in Table 2 .

Table 1. Matrix Converter switching table and the corresponding voltage and current outputs

\begin{tabular}{||c||c||c||c||}
\hline \hline $\begin{array}{c}\text { SWITCHING } \\
\text { CONFIGURATION }\end{array}$ & $\mathbf{A} \mathbf{B} \mathbf{C}$ & $\boldsymbol{V}_{\boldsymbol{A} \boldsymbol{B}} \boldsymbol{V}_{\boldsymbol{B} \boldsymbol{C}} \boldsymbol{V}_{\boldsymbol{C A}}$ & $\boldsymbol{I}_{\boldsymbol{A}} \boldsymbol{I}_{\boldsymbol{B}} \boldsymbol{I}_{\boldsymbol{C}}$ \\
\hline \hline+1 & $a b b$ & $v_{a b} 0-v_{a b}$ & $i_{A}-i_{A} 0$ \\
\hline \hline-1 & $b a a$ & $-v_{a b} 0 v_{a b}$ & $-i_{A} i_{A} 0$ \\
\hline \hline+2 & $b c c$ & $v_{b c} 0-v_{b c}$ & $0 i_{A}-i_{A}$ \\
\hline \hline+2 & $c b b$ & $-v_{b c} 0 v_{b c}$ & $0-i_{A} i_{A}$ \\
\hline \hline+3 & $c a a$ & $v_{c a} 0-v_{c a}$ & $-i_{A} 0 i_{A}$ \\
\hline \hline+4 & $a c c$ & $-v_{c a} 0 v_{c a}$ & $i_{A} 0-i_{A}$ \\
\hline \hline-4 & $b a b$ & $-v_{a b} v_{a b} 0$ & $i_{B}-i_{B} 0$ \\
\hline \hline+5 & $a b a$ & $v_{a b}-v_{a b} 0$ & $-i_{B} i_{B} 0$ \\
\hline \hline-5 & $c b c$ & $-v_{b c} v_{b c} 0$ & $0 i_{B}-i_{B}$ \\
\hline \hline & $b c b$ & $v_{b c}-v_{b c} 0$ & $0-i_{B} i_{B}$ \\
\hline \hline
\end{tabular}




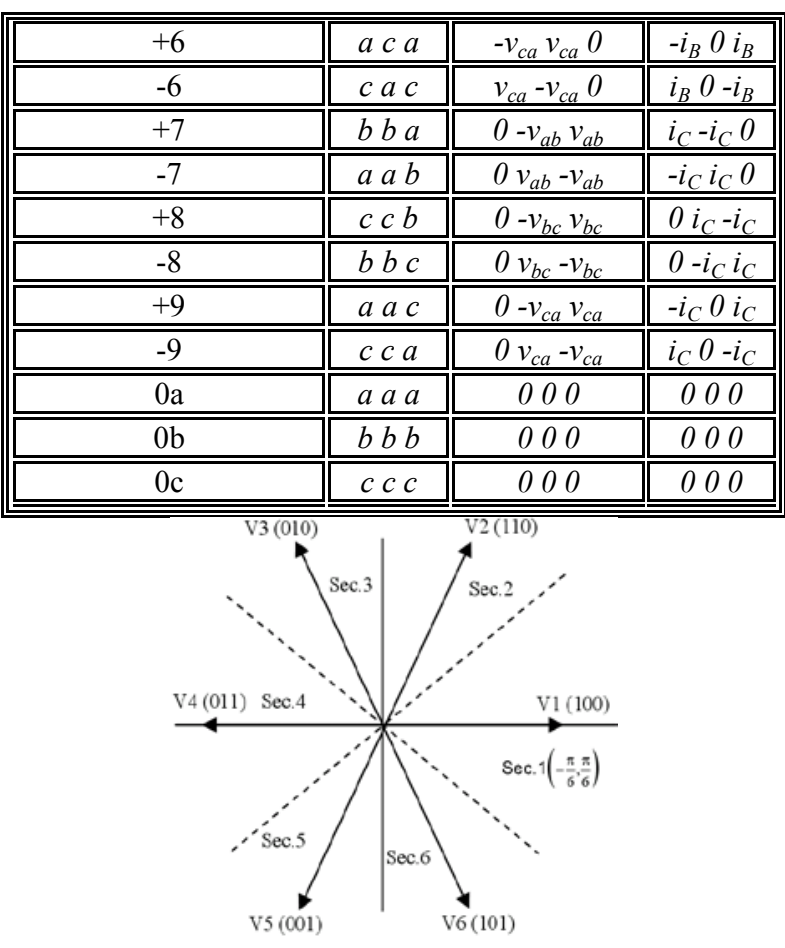

(a) Output voltage vectors
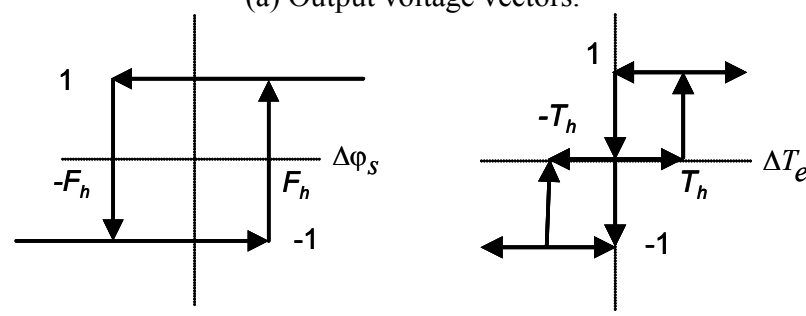

(b) Flux comparator.

(c) Three-level torque comparator.

Fig. 4. DTC definition of the voltage vectors and comparators.

Table 2. Matrix and DTC optimum switching table

\begin{tabular}{|c|c|c|c|c|c|c|c|c|c|c|c|c|c|}
\hline \multicolumn{2}{|c|}{\begin{tabular}{|c|} 
SECTOR \\
OF THE \\
INPUT \\
CURRENT \\
VECTOR \\
\end{tabular}} & \multicolumn{2}{|c|}{1} & \multicolumn{2}{|c|}{2} & \multicolumn{2}{|c|}{3} & \multicolumn{2}{|c|}{4} & \multicolumn{2}{|c|}{5} & \multicolumn{2}{|c|}{6} \\
\hline $\sin$ & $\left.\psi_{i}\right)$ & 1 & -1 & 1 & -1 & 1 & -1 & 1 & -1 & 1 & -1 & 1 & -1 \\
\hline \multirow{6}{*}{$\begin{array}{l}n \\
5 \\
0 \\
0 \\
0 \\
0 \\
00 \\
\frac{\pi}{0} \\
0\end{array}$} & $\mathrm{~V}_{1}$ & $\mid-3$ & 1 & 2 & -3 & -1 & 2 & 3 & -1 & -2 & 3 & -1 & -2 \\
\hline & $V_{2}$ & 9 & -7 & -8 & 9 & 7 & -8 & -9 & 7 & 8 & -9 & 7 & 8 \\
\hline & $\mathrm{V}_{3}$ & -6 & 4 & 5 & -6 & -4 & 5 & 6 & -4 & -5 & 6 & -4 & -5 \\
\hline & $V_{4}$ & 3 & -1 & -2 & 3 & 1 & -2 & -3 & 1 & 2 & -3 & 1 & 2 \\
\hline & $V_{5}$ & -9 & 7 & 8 & -9 & -7 & 8 & 9 & -7 & -8 & 9 & -7 & -8 \\
\hline & $\mathrm{V}_{6}$ & 6 & -4 & -5 & 6 & 4 & -5 & -6 & 4 & 5 & -6 & 4 & 5 \\
\hline
\end{tabular}

\section{Simulation results}

The simulation results of the sparse matrix converter feeding an induction machine load are presented in Fig. 5 and Fig. 6. Table 1 gives the list of specification elements of the circuit. Fig. 7 to Fig. 12 present the results simulation of the system and Table 2 present a summary of the results simulation for different speeds.
The output voltage Vabc of the converter is shown in Fig. 10a.

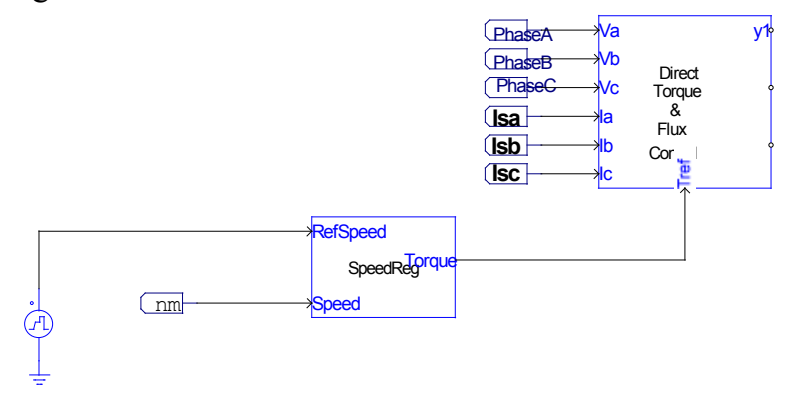

a)

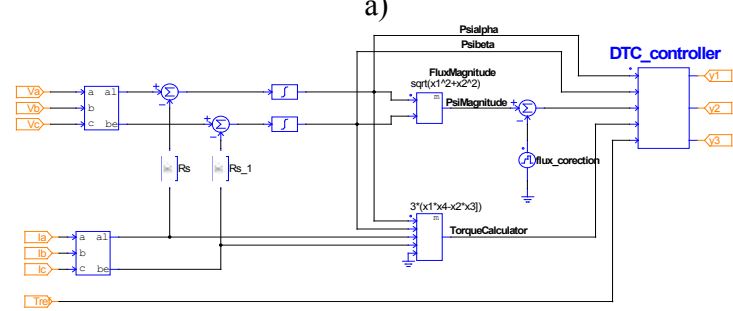

b)

Fig. 5. Structure of the DTC controller implemented in PSIM speed controller and the DTC module.

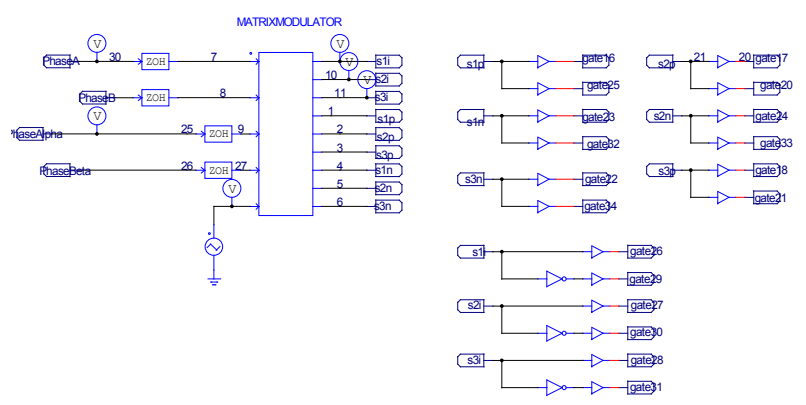

Fig. 6. Structure of the Matrix converter PWM controller implemented in PSIM.

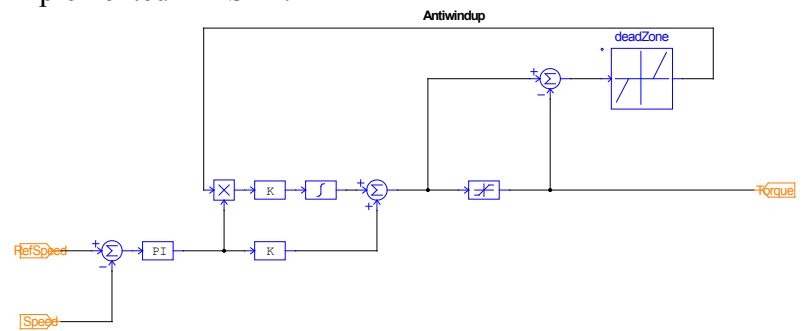

Fig. 7. Structure of the speed controller implemented in PSIM.

Figs. 8(a)-(b) show the phase 1 input current (ie) and its harmonic spectrum, respectively before filtering. The input current has a THD of $75.45 \%$ and its harmonic spectrum show that has high frequency harmonics. The output current has a THD of $2.74 \%$ is shown and its spectrum respectively in Figs. 7. (a)-(b). The output voltage (vs) of phase 1 and its harmonic spectrum are shown in Figs. 8. (a)-(b), respectively. It has a THD of $92.02 \%$ and show the presence of high frequency harmonics.

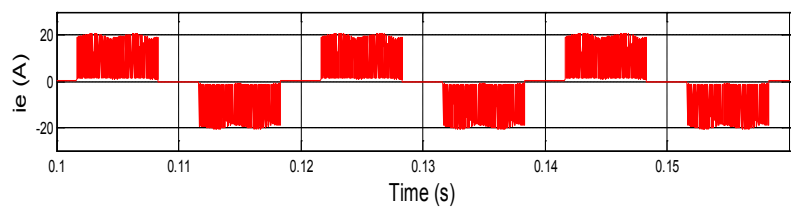


(a)

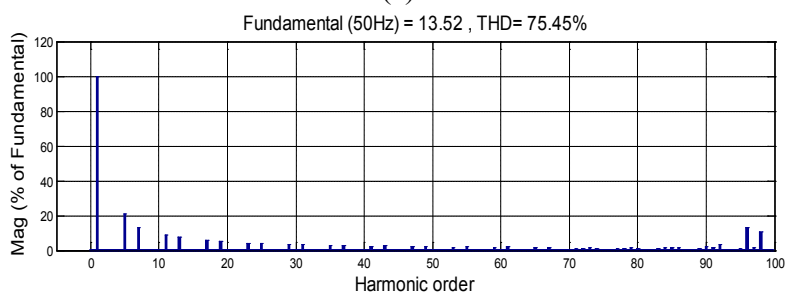

(b)

Fig. 8. Simulation results, (a) input current of Three Phase to three Phase Sparse Matrix Converter before filtering, (b) Harmonic Spectrum.

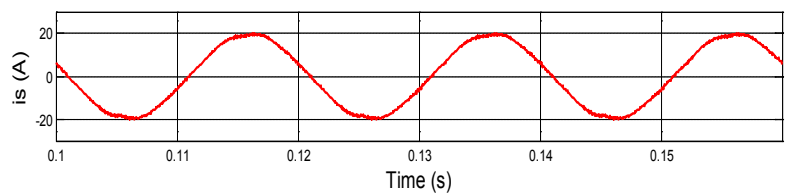

(a)

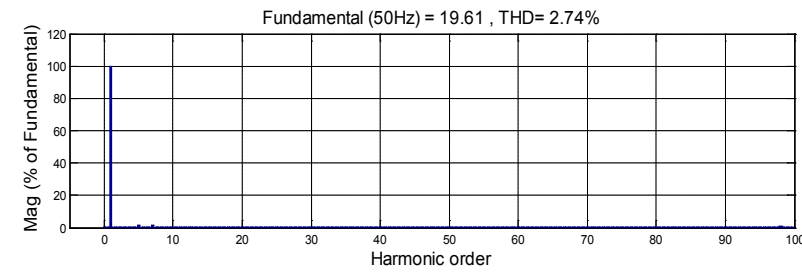

(b)

Fig. 9. Simulation results of Three Phase to three Phase Sparse Matrix Converter, (a) output current (b) Harmonic Spectrum.

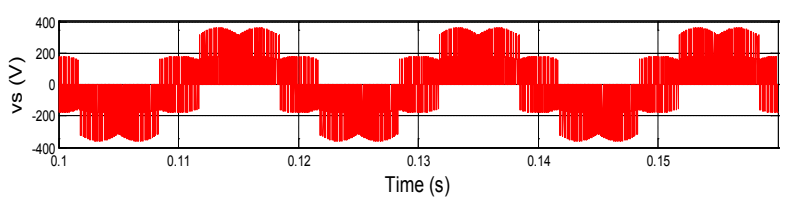

(a)

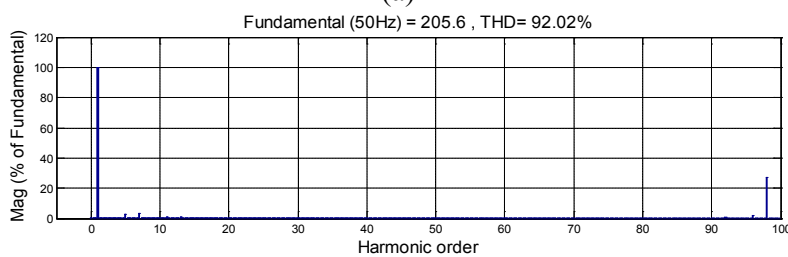

(b)

Fig. 10. Simulation results, (a) Output voltage of Three Phase Matrix Converter, (b) Harmonic Spectrum.
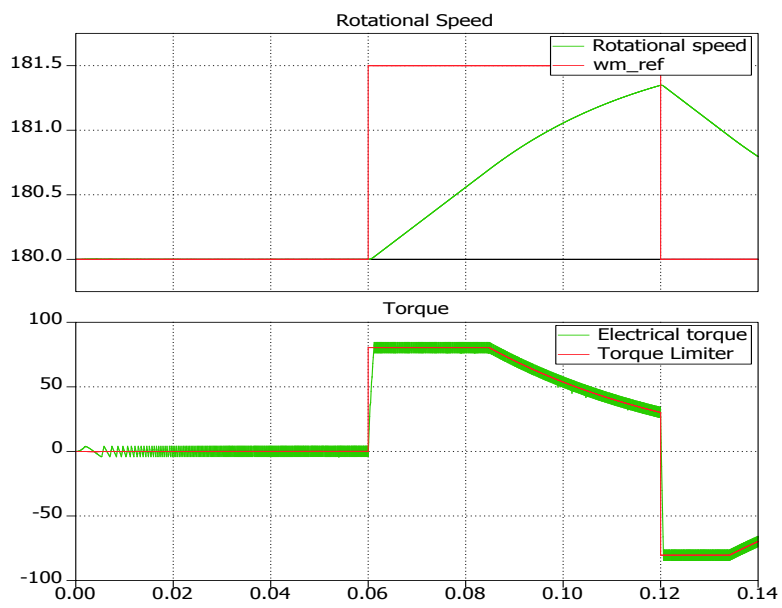

Fig.11. Simulation results, (a) reference speed of DTC electric drive ,(b) Torque of Drive.

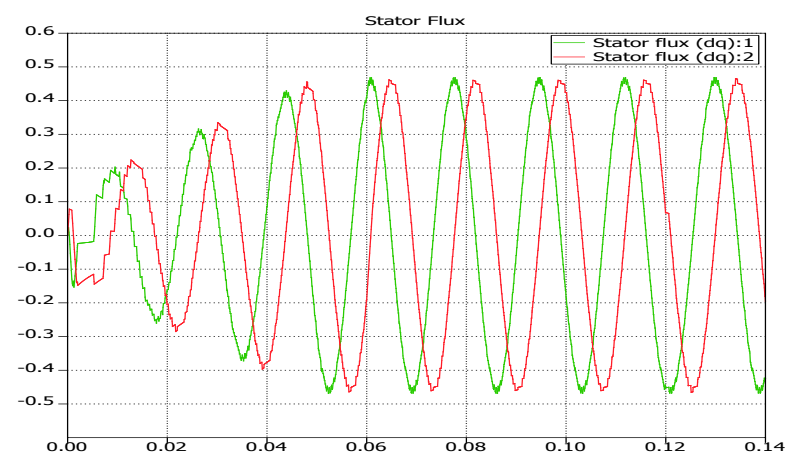

Fig. 12. Simulation results, IM flux.

The machine data used in simulation are given below:

$$
\begin{aligned}
& R_{s}=0.1062 ; R_{r}=0.0764 ; L_{l s}=0.2145 /(2 * \pi * 50) \\
& L_{l r}=L_{l s} ; L_{m}=5.834 /(2 * \pi * 50) ; p=2 ; J=2.8 \\
& F=0
\end{aligned}
$$

\section{Conclusions}

In this paper the topology of indirect matrix converter integrated in the structure of the HEV is analyzed and results simulation are obtained for direct torque control DTC with induction machine electric drive. Further, the operation of a three phase to three phase matrix converter synthesized using the DTC control has been detailed. Using a matrix converter the electric drive will provide sine wave input current and output voltage using various control technique.

The combination of the DTC control and the matrix converter offer us a very wide field of research especially in the study of reliability, maintainability, availability; faults tolerances and stability of these types of converters in considering their application for traction designated electric machines. The integration of DTC control is ensuring the optimization of conduction and switching losses with high performance operation of the converter and the machine. The matrix converter has advantages

- The possibility of reducing the number of switches forming the converter thus reducing the number of semi-conductors and subsequently losses.

These difficulties concerning the power electronics switching are reduced, switches of the input stage (rectifier) are reduced and the second stage of the converter switches as a standard inverter.

\section{References}

1. Benachour, E. M. Berkouk, M.O. Mahmoudi, DTCSVM control of induction machine fed by three level NPC matrix converter, $20168^{\text {th }}$ Internat. Conf. on Modelling, Identification and Control (ICMIC), Algiers, 628-633, (2016).

2. Venugopal, Fuzzy logic based DTC for speed control of Matrix Converter fed Induction Motor, 2010 IEEE Internat. Conf. on Power and Energy, Kuala Lumpur, 753-758, (2010). 
3. B.F. Mardani, M. Ardebili, DTC-SVM control strategy for induction machine based on indirect matrix converter in flywheel energy storage system, The $6^{\text {th }}$ Power Electronics, Drive Systems \& Technologies Conf. (PEDSTC 2015), Tehran, 352357, (2015).

4. N. Fazli, J. Siahbalaee, Direct torque control of a wind energy conversion system with permanent magnet synchronous generator and Matrix Converter, $20178^{\text {th }}$ Power Electronics, Drive Systems \& Technologies Conf. (PEDSTC), Mashhad, 2017, 166-171, (2017).

5. S.S. Sebtahmadi, H. Pirasteh, S.H. Aghay Kaboli, A. Radan, S. Mekhilef, A 12-Sector Space Vector Switching Scheme for Performance Improvement of Matrix-Converter-Based DTC of IM Drive, IEEE T. Power Electr., 30(7), 3804-3817 (2015).

6. V. Faraji, D. Arab Khaburi, A new approach to DTC-ISVM for induction motor drive system fed by indirect matrix converter, $20112^{\text {nd }}$ Power Electronics, Drive Systems and Technologies Conference, Tehran, 367-372, (2011).

7. S. A. Davari, F. Montazeri, D. A. Khaburi, A comparative study of matrix converter based DTC with complete vectors application and an improved predictive torque control using two-level inverter, 2009 Internat. Conf. on Electrical and Electronics Engineering - ELECO 2009, Bursa, pp. I-410-I-414, (2009).

8. T. Peng, M. Wen, Z. Li, Z. Xu, J. Yang, An improved DTC strategy for induction motors fed by direct matrix converter, Chinese Automation Congress (CAC), Wuhan,1766-1771, (2015).

9. D. Xiao, F. Rahman, A modified DTC for matrix converter drives using two switching configurations $200913^{\text {th }}$ European Conf. on Power Electronics and Applications, Barcelona, 1-10, (2009).

10. Z. Li, Simulation on Matrix Converter Fed Induction Motor DTC Drive System, Internat. Workshop on Intelligent Systems and App., 2009, Wuhan, 1-4, (2009).

11. V. Faraji, M. Aghasi, D. A. Khaburi, M. J. Ghorbani, A modified DTC for induction motor drive system fed by Indirect Matrix Converter using Active Learning Method, $2^{\text {nd }}$ Power Electronics, Drive Systems and Technologies Conf., Tehran, 356-361, (2011).

12. J. Zhang, L. Li, D. Dorrell, Y. Guo, Direct torque control with a modified switching table for a direct matrix converter based AC motor drive system, 2017 $20^{\text {th }}$ Internat. Conf. on Electrical Machines and Systems (ICEMS),Sydney, NSW, 1-6, (2017). 